\title{
THE EFFECT OF TECHNOLOGICAL PARAMETERS ON INTENSITY OF SHOT PEENING PROCESS OF 51CrV4 STEEL
}

\author{
Magdalena BUCIOR*, Lidia GAŁDA*, Feliks STACHOWICZ**, Władysław ZIELECKI* \\ "Faculty of Mechanical Engineering and Aeronautics, Department of Manufacturing Processes and Production Engineering, \\ Rzeszow University of Technology, Powstańców Warszawy 8, 35-959 Rzeszów, Poland \\ "Faculty of Mechanical Engineering and Aeronautics, Department of Materials Forming and Processing, \\ Rzeszow University of Technology, Powstańców Warszawy 8, 35-959 Rzeszów, Poland \\ $\underline{\text { magdabucior@prz.edu.pl, lgktmiop@prz.edu.pl, stafel@prz.edu.pl, wzktmiop@prz.edu.pl }}$
}

received 12 May 2015, revised 18 July 2016, accepted 20 July 2016

\begin{abstract}
In the paper the effect of selected technological parameters of shot peening on process intensity of $51 \mathrm{CrV} 4$ steel was presented. The experiments were conducted according to statistical 3-level completed plan PS/DC 32. Technological parameters were changed in the range: shot peening time $t=1-3 \mathrm{~min}$ and pressure $p=0.2-0.4 \mathrm{MPa}$. In the article the analysis of experiment reproducibility, impact parameters significance and adequacy of equation were done. As the result of investigations the adequate equation was obtained describing the effect of technological parameters. Significant influence on process intensity was found in case of pressure and interaction of both analyzed technological parameters. The biggest energy of stream shots was gained at the maximum pressure of $0.4 \mathrm{MPa}$ and the shot peening time of 3 minutes. As the result of analysis according to design of experiment (DOE) the adequate equation describing the dependencies between technological parameters and process intensity was found.
\end{abstract}

Keywords: Almen Intensity, Shot Peening, Plan PS/DC $3^{2}$

\section{INTRODUCTION}

Machines parts operating under cyclic loading are particularly exposed to cracking. Prevention of this harmful phenomenon could be realized by the appropriate materials and suitable treatment application.

The vibrating screener used for the separation of the finegrained and wet materials worked on the basis of parametric resonance. During exploitation of separating screener the large deformation and cracks occurred near the edges of sieve plate (Śledź et al., 2014). The traditional steel is usually used in such type of the screeners. The comparative examinations (Śledź et al., 2013; 2014; 2015) allowed to choose the most appropriate material for the sieve plate. The spring steel 51CrV4 was selected and the shot peening technology was proposed to improve the fatigue strength. This method is widely used to increase the fatigue strength of materials by compressive residual stress creation in their surface layers (Llaneza and Belzunce, 2015; Tekeli, 2002; Torres and Voorwald, 2002; Zielecki, 1987). The reasons for compressive residual stresses arising during shot peening are plastic deformation, temperature and structural transformations (Nakonieczny, 2002). Because plastic deformations after the strengthening process form the homogenous layer with compressive stresses in metal surface the increase in durability of processed parts occures.

The new peening methods are also discovered that could be more effective than classical shot peening. Soyama and Takeo (2016) found that cavitation peening led to the fatigue life enhancement of duralumin plate with a hole. Shot peening was succesfully implemented in chromium coated elements processing to restore the fatigue strength that was impaired by chromium electroplating (Korzynski et al., 2009). Application of the shot peening to process the AZ91 alloy surface allowed to enhance up to $87 \%$ greater fatigue strength compared to turned surface (Korzynski, 2011). Shot peening was also combined with other processes to get better fatigue performance. Lv et al. (2016) combined the shot peening with laser surface melting treatments and found that the shot peening intensity strongly affected the microhardnes, residual stresses and fatigue life of processed $20 \mathrm{CrMnTi}$ steel gears. Shot peening is commonly used for surface cleaning after previous treatment to obtain premium quality (Zyzak, 2010) or to assure the high adhesion of the coating.

Shot peening intensity is the measure of the shot stream energy. The process intensity is also one of the basic measure ensuring the process repeatability. The energy of the shot stream is directly related to the compressive stresses that are imparted in the machined parts (http://www.metalimprovement.com). The intensity can be increased by the large shots application, the velocity enhancement of shot stream, the impact angle modification and also by the extension of process time.

Taking into account the high cost and experiments duration the suitable planning, realization and analysis seem to be very important task (Jebahi et al., 2016; Skowronek, 2007). Experimental design and optimization are tools often used to examine different type of problems in research, development and production (Lundstedt et al., 1988). The main aim of planning of experiments is to obtain the answer for the question: how to plan the experiment regarding possible low costs and a lot of useable information at the same time (Pietraszek, 2004). There are a number of technical limitations in machines technology so the DOE enables the test realization and obtaining results that could 
be impossible to get in any other way or could determine high costs. It is possible to find the appropriate design of the experiment allowing the rational application (Korzyński, 2013). The mathematical basis and methodology of results elaboration is well described in technical literature. The main classification of experimental plans is for dynamic and static type (Polański, 1984). Also numerical simulation of shot peening process could be provided as the suplementation of experiment but the matter of simplification assumption of the model always remain. Developed robust simulation is promising technique that enables to get properly simulated shot peening models (Jebahi et al., 2016).

For the assessment of the influence of technological parameters the full 2-factorial design of 3-levels (PS/DC 32) was used. This plan enables the optimum achievement if it appears in examined area. The determined experiment designs are characterized by values of input factors in precisely described way that excludes the accidental choice. Such DOE is formulated to gain the possibly fast results with minimal costs. Great advantage of DOE is the facility of the mathematical results calculation (Korzyński, 2013).

\section{METHODS}

The effect of selected technological parameters of shot peening on process intensity was examined with $51 \mathrm{CrV} 4$ usage. Chemical composition of $51 \mathrm{CrV} 4$ steel is presented in Tab. 1. The experiments were conducted according to the static 2-factorial 3-level completed plan PS/DC 32 . All experiments were realized with triple repetition. The significance level of $a=0.05$ was assumed. The process intensity was assessed by value of the Almen strip deflection $f_{A}$ measured with the usage of Almen Gage TSP-3 (Fig. 1a) in compliance with SAE standard J442_201302 (2013). According to SAE standard J443_201006 it is recommended that the test strip of A type should be applied for intensities that produce arc heights of $0.10 \mathrm{~mm}$ to $0.60 \mathrm{~mm}$ (SAE standard J443_201006, 2010). Because of the thickness of the peened sample and the medium process intensity the control samples A-2 with hardness of 44-50 HRC were used. The Almen strips were peened on one side only. The residual compressive stresses brought by shot peening caused the Almen strip bend in arc convex towards processed side (Fig. 1b). Almen strip arc height $f_{A}$ is the function of the shot stream energy and it is the quantity measure of intensity. Steel and control samples were processed in device shown in Fig. 2.

Tab. 1. Chemical composition of $51 \mathrm{CrV} 4$ steel

\begin{tabular}{|c|c|c|c|c|c|c|c|c|}
\hline \multicolumn{1}{|c|}{ Chemical composition \% } \\
\hline Steel & $\mathrm{C}$ & $\mathrm{Mn}$ & $\mathrm{Si}$ & $\mathrm{S}$ & $\mathrm{P}$ & $\mathrm{Cr}$ & $\mathrm{Ni}$ & $\mathrm{V}$ \\
\cline { 2 - 9 } 51CrV4 & $0.46-$ & $0.5-$ & $0.15-$ & 0.03 & 0.03 & $0.8-$ & 0.4 & $0.1-$ \\
& 0.54 & 0.8 & 0.4 & $\mathrm{max}$ & $\mathrm{max}$ & 1.1 & $\max$ & 0.2 \\
\hline
\end{tabular}

The plan of the experiment implies the adoption of three levels of controlling factors coded as $\mathrm{x}$ :

- the minimum (-),

- the central $(0)$,

- the maximum $(+)$,

and their normalization is described by the following relations:

$x_{k}=\frac{\hat{x}_{k}-\hat{x}_{k 0}}{\Delta \hat{x}_{k}}$, $\hat{x}_{k 0}=\frac{\hat{x}_{k \max }+\hat{x}_{k \min }}{2}$,

$\Delta \hat{x}_{k}=\frac{\hat{x}_{k \max }-\hat{x}_{k \min }}{2}$,

where: $x_{k}$ - coded form of input factor, $\hat{x}_{k}$ - real value of input factor, $\hat{x}_{k 0}$ - the central value of the factor in real scale, $\Delta \hat{x}_{k}$ - step change of controlled factor.

a)

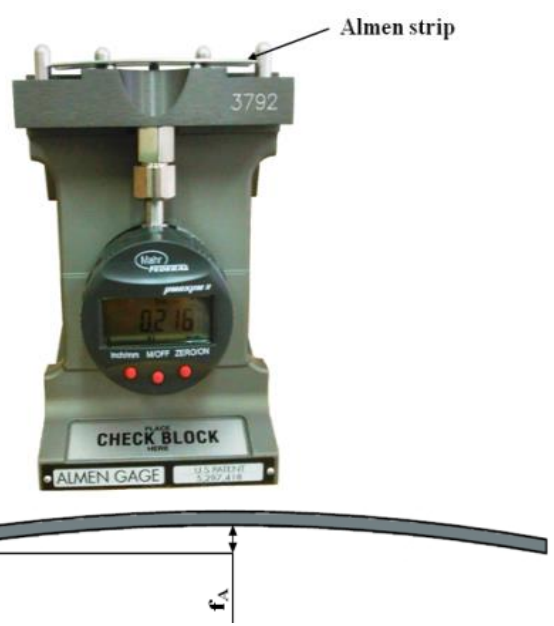

Fig. 1. Photo of Almen gage TSP-3 (a) and scheme of Almen strip after shot peening (b)

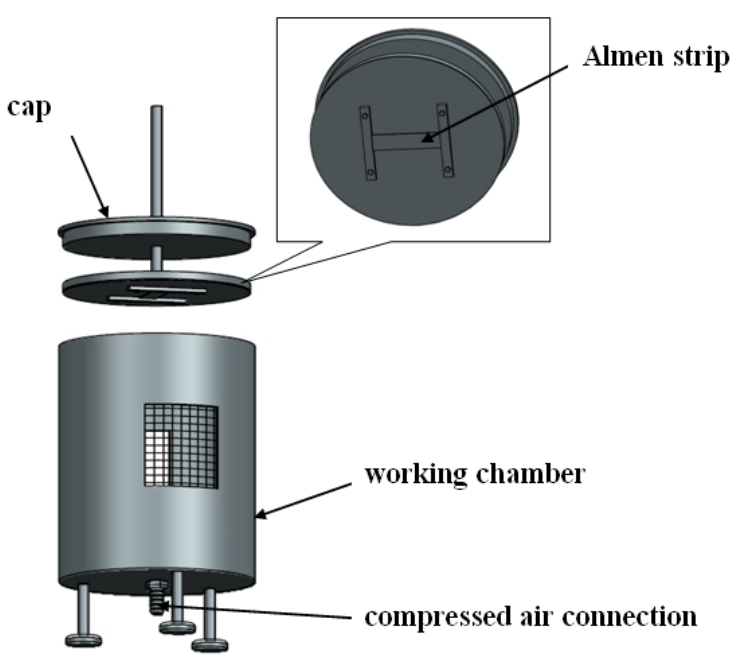

Fig. 2. Device for shot peening process

Technological parameters were changed in the range: shot peening time $t=1-3 \mathrm{~min}$ and pressure $p=0.2-0.4 \mathrm{MPa}$. The values of these parameters are presented in Tab. 2. In the experiment the constant parameters were: the ball diameter $d_{b}=2$ $\mathrm{mm}$ and the distance from the strip to the nozzle I $=250 \mathrm{~mm}$. In the preliminary test the biggest degree of surface coverage was obtained with the ball diameter equal to $2 \mathrm{~mm}$.

Tab. 2. Values of technological parameters set in the experiment

\begin{tabular}{|c|c|c|}
\hline Input factors & $\mathbf{t}, \mathbf{m i n}$ & $\mathbf{p}, \mathbf{M P a}$ \\
\hline the minimum $(-)$ & 1 & 0.2 \\
\hline the central $(0)$ & 2 & 0.3 \\
\hline the maximum $(+)$ & 3 & 0.4 \\
\hline Output factor & \multicolumn{2}{|c|}{$\mathrm{f}_{\mathrm{A}}$} \\
\hline
\end{tabular}




\section{RESULTS AND DISCUSSION}

The matrix of the 3-level completed plan PS/DC $3^{2}$ with two input factors $x_{1}, x_{2}$, their interactions and average process intensity is presented in Tab. 3.

Tab. 3. Matrix of plan PS/DC $3^{2}$ and results

\begin{tabular}{|c|c|c|c|c|c|c|c|c|}
\hline $\mathbf{N r}$ & $\mathbf{x}_{\mathbf{0}}$ & $\mathbf{x}_{1}$ & $\mathbf{x}_{2}$ & $\mathbf{x}_{1}{ }^{2}$ & $\mathbf{x}_{2}{ }^{2}$ & $\mathbf{x}_{1} \mathbf{x}_{2}$ & $\overline{\mathbf{f}_{\mathbf{A i}}}$ & $\boldsymbol{\sigma}$ \\
\hline 1 & + & + & + & + & + & + & 0.474 & 0.024 \\
\hline 2 & + & + & 0 & + & 0 & 0 & 0.330 & 0.020 \\
\hline 3 & + & + & - & + & + & - & 0.162 & 0.020 \\
\hline 4 & + & 0 & + & 0 & + & 0 & 0.358 & 0.005 \\
\hline 5 & + & 0 & 0 & 0 & 0 & 0 & 0.274 & 0.026 \\
\hline 6 & + & 0 & - & 0 & + & 0 & 0.143 & 0.019 \\
\hline 7 & + & - & + & + & + & - & 0.274 & 0.014 \\
\hline 8 & + & - & 0 & + & 0 & 0 & 0.162 & 0.024 \\
\hline 9 & + & - & - & + & + & + & 0.089 & 0.003 \\
\hline \\
where: $x_{1}-$ coded value of time t, $x_{2}-$ coded value of pressure $p$, \\
\hline \\
$f_{A i}-$ average of three measurement results of Almen strip in the i-th \\
experiment, $\sigma$ - standard deviation.
\end{tabular}

Methodology of 3-level plan requires to perform a few steps. The central values of time $t$ and pressure $p$ were calculated by the following relations:

$$
\begin{aligned}
& \hat{x}_{10}=\frac{t_{\max }+t_{\min }}{2}=2 \mathrm{~min}, \\
& \hat{x}_{20}=\frac{p_{\max }+p_{\min }}{2}=0.3 \mathrm{MPa} .
\end{aligned}
$$

Variability units of time $t$ and pressure $p$ were calculated by the following relations:

$$
\begin{aligned}
& \Delta \hat{x}_{1}=\frac{t_{\max }-t_{\min }}{2}=1 \mathrm{~min}, \\
& \Delta \hat{x}_{2}=\frac{p_{\max }-p_{\min }}{2}=0.1 \mathrm{MPa} .
\end{aligned}
$$

Coding factors of time $t$, pressure $p$ and Almen intensity $f_{A}$ were got by the following relation:

$x_{1}=\frac{\hat{x}_{1}-\hat{x}_{10}}{\Delta \hat{x}_{1}}=\frac{t-2}{1} \mathrm{~min}$,

$x_{2}=\frac{\hat{x}_{2}-\hat{x}_{20}}{\Delta \hat{x}_{2}}=\frac{p-0.3}{0,1} M P a$,

$y=f_{A}$.

As the result of experiments conducted according to the plan PS/DC $3^{2}$ and matematical analyses the function was obtained:

$y=f(x)$.

The function $\mathrm{f}(\mathrm{x})$ is approximated by a polynomial function and represents a good description of the relationship between the experimental variables and gives the response in a limited experimental domain (Lundsted, 1998). To determine the function optimum the quadratic terms should stay in the model. It is possible to determine non-linear relationships between the experimental variables and responses by introducing these terms in the model. The polynomial function below describes a quadratic model with two variables $\mathrm{x}_{1}$ and $\mathrm{x}_{2}$ :

$y=b_{0}+b_{1} x_{1}+b_{2} x_{2}+b_{11} x_{1}^{2}+b_{22} x_{2}^{2}+b_{12} x_{1} x_{2}$,

where: $b_{0}, \ldots, b_{12}$ - regression factors.
The regression factors were calculated according to formulas:

$b_{0}=\frac{1}{9}\left(-\bar{y}_{1}+2 \bar{y}_{2}-\bar{y}_{3}+2 \bar{y}_{4}+5 \bar{y}_{5}+2 \bar{y}_{6}-\bar{y}_{7}+2 \bar{y}_{8}-\right.$

$\left.\bar{y}_{9}\right)=0.262$,

$b_{1}=\frac{1}{6}\left(\bar{y}_{1}+\bar{y}_{2}+\bar{y}_{3}-\bar{y}_{7}-\bar{y}_{8}-\bar{y}_{9}\right)=0.074$,

$b_{2}=\frac{1}{6}\left(\bar{y}_{1}-\bar{y}_{3}+\bar{y}_{4}-\bar{y}_{6}+\bar{y}_{7}-\bar{y}_{9}\right)=0.119$,

$b_{11}=\frac{1}{6}\left(\bar{y}_{1}+\bar{y}_{2}+\bar{y}_{3}-2 \bar{y}_{4}-2 \bar{y}_{5}-2 \bar{y}_{6}+\bar{y}_{7}+\bar{y}_{8}+\right.$

$\left.\bar{y}_{9}\right)=-0.010$,

$b_{22}=\frac{1}{6}\left(\bar{y}_{1}-2 \bar{y}_{2}+\bar{y}_{3}+\bar{y}_{4}-2 \bar{y}_{5}+\bar{y}_{6}+\bar{y}_{7}-2 \bar{y}_{8}+\right.$

$\left.\bar{y}_{9}\right)=-0.005$,

$b_{12}=\frac{1}{4}\left(\bar{y}_{1}-\bar{y}_{3}-\bar{y}_{7}+\bar{y}_{9}\right)=0.032$.

In order to assess the relevance of regression factors the following values were calculated - eqs. (19-25).

$\mathrm{G}$ - empirical value was calculated by the relation:

$G=\frac{S^{2}(y)_{i \max }}{\sum_{i=1}^{N} S^{2}(y)_{i}}=0.2039$,

where: $S^{2}(y)_{i}$ - variation of measured values, $N$ - total number of experiments according to planned matrix.

The numbers of freedom degrees were calculated according to formulas:

$f_{1}=N=9$,

$f_{2}=r-1=2$,

where: $G_{k r}$ - critical value specified by Cochran's statistic:

$G_{k r}=G_{\left(\alpha ; f_{1} ; f_{2}\right)}=0.4775$.

In case of $G<G_{k r}(0.2039<0.4775)$ the experiment was realised in sufficient reproducibility.

To evaluate the relevance of regression factor some necessary values were caltulated. The number of freedom degrees $f$, the value of the coefficient form Student's $t$ statistics $t_{k r}$ and critical value $b_{\mathrm{kr}}$ were calculated by the relations:

$f=N(r-1)=18$,

$t_{k r}=t_{(\alpha ; f)}=2.1009$,

$b_{k r}=t_{(\alpha ; f)} \sqrt{\frac{s^{2}(y)}{N r}}=0.0076$.

In case of $\left|b_{k}\right|>b_{k k r}$ the regression coefficient has significant influence otherwise the factor was rejected.

As the effect of calculation the assesment of regression coefficient relevance was done and the results are presented in Tab. 4.

Tab. 4. Results of significance assesment

\begin{tabular}{|c|c|}
\hline Regression factors & Relevance \\
\hline$b_{0}$ & significant \\
\hline$b_{1}$ & significant \\
\hline$b_{2}$ & significant \\
\hline$b_{11}$ & significant \\
\hline$b_{22}$ & insignificant \\
\hline$b_{12}$ & significant \\
\hline
\end{tabular}

After the reduction of insignificant regression factors the func- 
tion is as follow:

$y=0.262+0.074 x_{1}+0.119 x_{2}-0.010 x_{1}^{2}+0.032 x_{1} x_{2}$

After decoding and calculation the searching equation representing the theoretical model is presented below:

$f_{A}=-0.091-0.010 t^{2}+0.018 t+0.55 p+0.32 t p$.

The adequatness of obtained equation was examined with application of the Fischer-Snedecor statistics. Firstly, the variance adequatness was calculated with formula:

$S_{a d}^{2}(y)=\frac{r \sum_{i=1}^{N}\left(\hat{y}_{i}-\bar{y}_{i}\right)^{2}}{N-k-1}=0.0009$,

where: $r$ - number of replication, $\hat{y}_{i}-$ values calculated from the regression equation for all levels of input factors, $\bar{y}_{i}$ - average of measured values in i-th experiment, $\mathrm{N}$ - total number of experiments, $\mathrm{k}$ - number of regression equation expressions (without free expresssion) after rejection the insignificant expressions.

Next the empirical value of the $F$ coefficient was calculated and compared to critical value Fkr got from the statistics $\mathrm{F}_{\mathrm{kr}}=F_{\left(\alpha ; f_{1} ; f_{2}\right)}=F_{(0.05 ; 4 ; 18)}=2.9277$.

$F=\frac{S_{a d}^{2}(y)}{S^{2}(y)}=2.5381$.

The obtained regression equation was adequate because $\mathrm{F}<\mathrm{F}_{\mathrm{kr}}(2.5381<2.9277)$ at the assumed significance level $a=0.05$. Graphically the obtained relations are presented in Fig. 3.

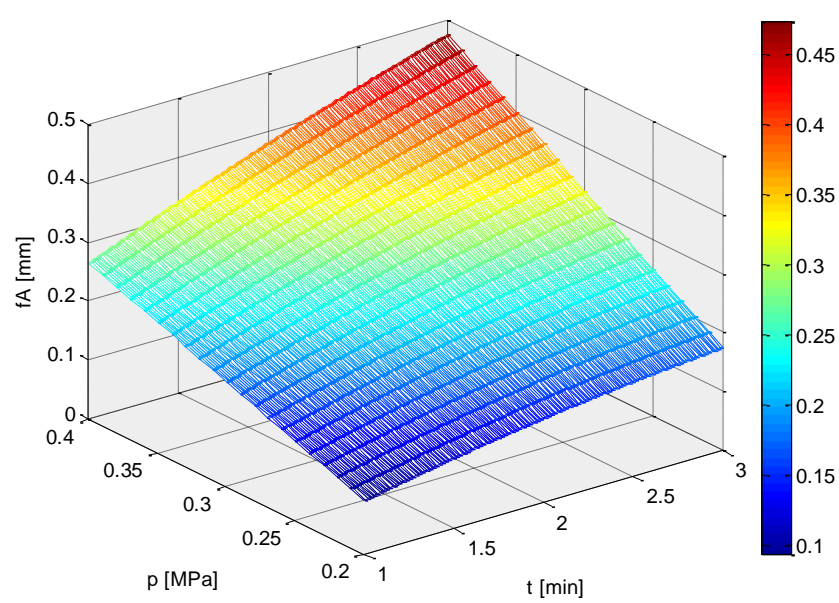

Fig. 3. The effect of technological parameters of shot peening on process intensity of $51 \mathrm{CrV} 4$ steel

Duration of the shot peening in the analysed range influenced the process intensity but not as much as the pressure. The maximum value of $f_{A}=0.474 \mathrm{~mm}$ was obtained at the highest settings of both technological parameters while the minimum $f_{A}=$ $0.089 \mathrm{~mm}$ was at the lowest values of shot peening technological parameters. For the implementation in production companies the most interesting are technologies which are economically explained so taking into account the process time the best variant could be at minimum $t=1$ min but maximum $p=0.4 \mathrm{MPa}$. Then the process intensity is equal to $0.274 \mathrm{~mm}$ and is the same as at $t$ $=2$ min and $p=0.3 \mathrm{MPa}$ and also close to the value obtained at $t$ $=3 \mathrm{~min}$ and $p=0.3 \mathrm{MPa}\left(\mathrm{f}_{\mathrm{A}}=0.33 \mathrm{~mm}\right)$. But if there is greater intensity needed the time duration should be longer at least $3 \mathrm{~min}$ and pressure higher. The maximum pressure of $0.4 \mathrm{MPa}$ gives the highest energy of the shot stream but the time of exposition is important too.

The values of shot peening intensity $f_{A}$ obtained in the experiment and calculated from the model are presented in Fig. 4.

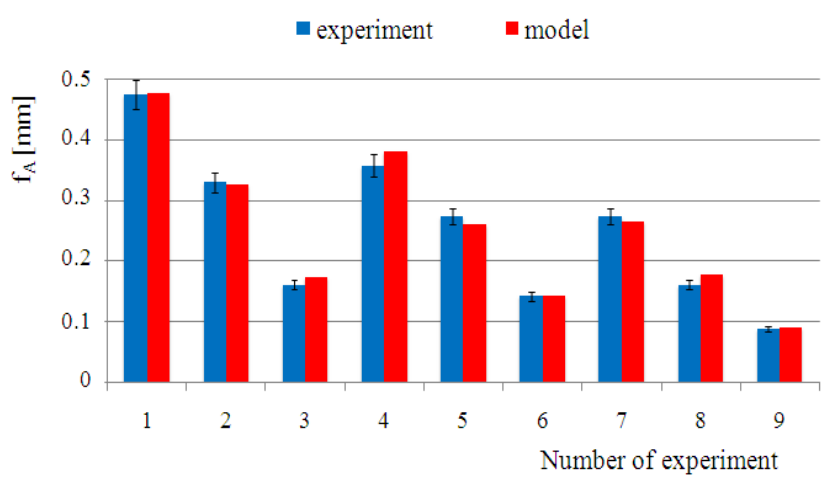

Fig. 4. The theoretical and experimental values of shot peening intensity $f_{A}$ according to $P S / D C 3^{2}$

Comparing the theoretical and experimental values the good agreement is observed. Almost all values calculated from the model are in the limits of $5 \%$ error amount of measured values obtained in the experiments.

\section{CONCLUSION}

The most significant effect on process intensity was found in case of pressure and interaction of both analyzed technological parameters. The maximum value of shot peening intensity was obtained at maximum technological parameters values $p=0.4$ $\mathrm{MPa}$ and $\mathrm{t}=3 \mathrm{~min}$. The time duration of the process is important factor as well. The analysis of experiment repeatability, impact significance and adequacy of equation were made according to statistical 3-level completed plan PS/DC 32. As the result of investigations the adequate equation was obtained describing the effect of technological parameters. The theoretical model was in accordance with experimental data.

\section{REFERENCES}

1. Jebahi M., Gakwaya A., Leveskue J., Mechri O., Ba K. (2016), Robust methodology to simulate real shot peening process using discrete-continuum coupling method, International Journal of Mechanical Sciences, 107, 21-33.

2. Korzyński M. (2013), Experiment methodology, WNT, Warszawa (in Polish).

3. Korzynski M., Dzierwa A., Pacana A., Cwanek J. (2009), Fatigue strenght of chromium coated elements and possibility of its improvement with ball peening, Surface \& Coatings Technology, 204, 615-620.

4. Korzynski M., Zarski T., Korzynska K. (2011), Surface layer condition and the fatigue strenght of an AZ91 alloy after ball peening, Journal of Materials Processing Technology, 211, 1982-1988.

5. Llaneza V., Belzunce F.J. (2015), Study of the effect produced by shot peening on the surface of quenched and tempered steels: roughness, residual stresses and work hardening, Applied Surface Science, 356, 475-485. 
7. Lundstedt T., Seifert E., Abramo L., Thelin B., Nyström A., Pettersen J., Bergman R. (1998), Experimental design and optimization. Chemometrics and Intelligent Laboratory Systems, 42, 3-40.

8. Lv Y., Lei L., Sun L. (2016), Influence of different combined severe shot peening and laser surface melting treatments on the fatigue performance of $20 \mathrm{CrMnTi}$ steel gear, Materials Science \& Engineering A, 658, 77-85.

9. Metal Improvement Company, (2005), Shot peening applications http://www.metalimprovement.com//premium/PDF/greenbook_v9/eng lish/Chapter\%2011.pdf (dostęp: 03 marzec 2015).

10. Nakonieczny A. (2002), Surface treatment by dynamic plastic deformation. Shot peening. Instytut Mechaniki Precyzyjnej, Warszawa (in Polish).

11. Pietraszek J. (2004), Experiment planning. Opportunity or necessity. http://www.statsoft.pl/Portals/0/Downloads/doe.pdf (in Polish), (dostęp 05 marzec 2015).

12. Polański Z. (1984), Experiment planning in technique, PWN, Warszawa (in Polish).

13. Skowronek A. (2007), Optimization of elastic experiment plan generativity. Czasopismo Techniczne. Informatyka, Wydawnictwo Politechniki Krakowskiej, 63-74 (in Polish).

14. Śledź M., Bąk Ł., Zielecki W. (2014), The effect of shot peening on fatigue strength of selected steel sheets, Publishing House of Rzeszow University of Technology, Monograph: Selected issues and problems in mechanical engineering, Rzeszów, $69-83$ (in Polish).

15. Śledź M., Stachowicz F., Zielecki W. (2015), The effect of shot peening on the fatigue strength of steel sheets, Metallic Materials, 53, 91-95.

16. Śledź, M., Bąk, Ł., Stachowicz, F., Zielecki, W. (2013), Analysis of the effect of shot peening on mechanical properties of steel sheets used as screener sieve materials, Journal of Physics: Conerence Series, 451, 012029.
17. Soyama H., Takeo F. (2016), Comparison between cavitation peening and shot peening for extending the fatigue life of a duralumin plate with a hole, Journal of Materials Processing Technology, 227, 80-87.

18. Tekeli S. (2002), Enhancement of fatigue strength of SAE 9245 steel by shot peening, Materials Letters, 57, 604-608.

19. Torres M. A. S., Voorwald H. J. C. (2002), An evaluation of shot peening, residual stress and stress relaxation on the fatigue life of AISI 4340 steel, International Journal of Fatigue, 24, 877-886.

20. Zielecki W. (1987), The effect of shot peening intensity on fatigue strength and surface layer properties of $50 \mathrm{HF}$ steel, Zeszyty Naukowe Politechniki Rzeszowskiej, Mechanika, 14, 35-40 (in Polish)

21. Zyzak P. (2010), Characteristic of a shot stream in a rotor cleaning machine, Archives of Metallurgy and Materials, 55 (3), 977-984.

22. SAE standard J442_201302 (2013) Test Strip, Holder, and Gage for Shot Peening, SAE International.

23. SAE standard J443_201006 (2010) Procedures for Using Standard Shot Peening Almen Strip, SAE International.

Acknowledgement: This work was supported by the European Research Agency - FP7-PEOPLE-2011-IAPP - Marie Curie Industry - Academia Partnerships and Pathways, grant agreement No. 284544. 